\title{
Learning about noticing, by, and through, noticing
}

\author{
John Mason ${ }^{1}$ (D) \\ Accepted: 28 September 2020 / Published online: 12 October 2020 \\ (c) The Author(s) 2020
}

\begin{abstract}
Aspects of noticing which are often overlooked are brought to the surface and illustrated by accounting-for three accountsof specific phenomena, two of which readers are invited to experience for themselves. These are used as a springboard for both illustrating the Discipline of Noticing as a method of sensitising oneself to notice possibilities for action, and reporting insights achieved through its use. This includes augmenting the discourse of Dual Systems Theory to include S1.5 (emotion) and S3 (creative insight) and linking it to a six-fold structure of the human psyche (enaction, affect, cognition, attention, will and witness). The aim is to enrich the discourse in which to account-for incidents as experienced by teachers themselves, and incidents observed by teachers and other researchers. The paper ends by distinguishing between measurement-based research validation, and phenomenologically-based validation which is part of the discipline of noticing.
\end{abstract}

Keywords Noticing $\cdot$ Discipline of noticing $\cdot$ Dual systems theory extended $\cdot$ Attention $\cdot$ Will $\cdot$ Witness $\cdot$ Six-fold human psyche $\cdot$ Phenomenology $\cdot$ Validation

\section{Introduction}

The Discipline of Noticing arose as an articulation of the sense I made of a lecture by J. G. Bennett (1976) in 1972. It took some 30 years for me to reach my articulation (Mason 2002), based on practices developed, refined, and honed both in the Centre for Mathematics Education at the Open University, and through my personal work. Here I want to draw attention to some aspects of Noticing as a practice and as a discipline which may be overlooked as teacher-noticing displaces personal noticing as the focus. I end with a rearticulation of some personal insights developed over the last 5 or so years about the structure of the human psyche, based on noticing of myself, but often confirmed in literature.

The Discipline of Noticing is foremost a systematic method for conducting research into one's own practice. As such it is phenomenological in nature, being concerned with the lived experience of the practitioner. Unlike common research methods based on measurement and statistical analysis of numerical data, the method of validation of the outcomes of noticing are humanistic and long-term, rather

John Mason

j.h.mason@open.ac.uk

1 Open University and University of Oxford, 27 Elms Rd, Oxford OX2 9JZ, UK than statistical and situation specific. They are concerned with the individual, not the 'average'. Insights obtained by means of the Discipline of Noticing are re-validated in the experience of other people, not only by whether they find themselves noticing things that previously they had not noticed, but whether they have actions become available which enable them to act differently because of what they notice. Their validity, in turn, resides in whether those they work with find themselves noticing and acting differently.

There are many definitions of education, but in the end it must surely come down to those who are undergoing 'education' finding themselves more sensitised to notice pertinent features, and having actions become available to be enacted to which they have not previously had access. This transcends knowledge-based definitions of education, because it stresses that beyond knowing-about, knowing-how, knowing-when, and knowing-what to do in the abstract, which may perhaps be assessed by essays, what matters is knowing-to act in the moment (Mason \& Davis 2013).

The astute reader will have noticed, possibly even marked (Mason 2002), the use of the phrase 'those undergoing education' rather than the more usual 'those being educated' in the previous paragraph. For me education is not something that others do to us, but rather, consists of opportunities afforded us for educating ourselves, a stance taken particularly forcefully by Gattegno (1970, 1975/1988) who coined 
the expression only awareness is educable. By this he meant, at least in part, that what can be learned through cognition, supported by affect and enaction, is to be sensitised to discipline-related features, and to internalise appropriate actions. He used the term awareness to refer to the enabling of action, and applied it equally to subconscious somatic actions such as heart-rate etc., and to semi-conscious and conscious initiation of action.

True to my phenomenological principles, the first section introduces two opportunities for readers to catch themselves in the act of noticing. These will serve as data in what follows. One makes use of some reported data from a classroom, together with noticing responses to it; the other offers an exercise through which to notice for oneself how attention shifts, changing its very nature.

In addition to my own responses I include the responses of a colleague, Martina Metz who was kind enough to read an early draft and to record what she noticed as she worked through the manuscript.

Analysis of that data affords me opportunity to make connections with the mathematics education literature, and to re-articulate insights into the nature of human psyche arising from what I have noticed in and for myself. The paper ends by placing the form of validation of noticing in a wider context of validation of social science research, because this too seems to be overlooked in many accounts that purport to make use of noticing, with or without treating it as a discipline.

\section{Some data: opportunities to notice}

Because what matters to me is the lived experience, it is essential to begin with something that resonates with past experience. I offer two accounts: an incident recorded by another researcher, together with what I noticed in me in response, and an exercise taken from a Hungarian problem book.

\subsection{Incident}

The following word problem was given to some learners, as reported by Orit Zaslavsky (2010);

Sara is 5 years older than her brother David. Three years ago she was twice his age. How old are they now?

A learner answered that the ages were 8 and 13. Asked to explain her method, she said:

"I multiplied 5 by 2 and added 3. This way I got 13, which is Sara's age. David's age is 8".

Here we have an account-of an incident (Mason 2002). There is no embroidery, no theorising, no justification. The account is so direct that it seems reasonable to take it at face value, because of the lack of embroidery. It has the ring of truth, being recognisable as the sort of thing that actually happens in classrooms.

\subsection{Exercise}

What came up inside you as you read it?

\subsubsection{Experiences}

What I noticed was the immediate arising inside me of a desire to 'see' what the learner was seeing (why double the 5, which on first glance seemed to me to be inappropriate?), combined with a desire to see whether the implied 'method' would always work. I then worked it out in the particular, for myself and got the same answer. This made me more curious about what the learner was 'seeing'.

Martina: I had recently been working on subtraction, and found myself seeing Sara and David as points on a number line 5 units apart. I had a sense of a thick red segment of length 5 sliding long the number line (this only became articulate when I started to record what I had noticed). For the ends to be a doubling it was clear that the left end had to be at 5 , and that if the difference was to be different, for example, 4 rather than 5, doubling would happen at 4 .

These are also accounts-of, as they are cast in a discourse which is intended to enable readers to recognise the experience, perhaps through resonance, but possibly through dissonance. They report our lived experience, not emotion-based or judgemental claims drawing on technical terms from the literature. It is my hope and expectation that others might recognise the arising inside them of something similar. There are three sets of data here: the students' report on how they reached their answer; Martina and my accounts of response to this; the reader's responses to both the original and our accounts.

\subsubsection{Accounting-for the learner's explanation}

One way to account-for the learner's actions as she explained them is that she enacted the first action that became available: double the 5 and then add 3. However, working with Sufi stories (Shah 1964, 1978) has inspired me to look for two or more contrasting interpretations of actions, in order not to overlook the complexity of human beings. Things rarely have simple origins; apparent cause-and-effect is more frequently the coming together of a multitude of impulses and forces (Mason 2016, 2017). 
A different interpretation is based on Martina's account. Seeing or having a sense of a sliding interval or difference, however inchoate, and intuiting that doubling requires the slider to start at the same place as the length of the slider, leads to doubling the 5. Attention shifted from focus on the difference, to imagining it laid out on the number line so as to be mentally or physically manipulable.

Another way to account-for the learner's actions is to conjecture that she supposed (whether being explicitly aware of the supposition as a supposition, or not) that David was 5 and Sara was 10. Then 3 years later, they will indeed be 8 and 13 . So the act of doubling the 5 could be a conjecture, seen as a trying an example. Because 'it worked', no further thinking was called for.

Although quite similar to the first interpretation, the third is subtly different, and is suggestive of a quite different disposition towards such a task. In the first, the 5 is simply a number on which to act, and in the presence of the words 'twice as old as', multiplication by 2 is a natural and automatic action, whereas in the second, there may be a 'sense' of the 5 as an age which at some time in the past, was doubled.

\subsection{Exercise}

Evaluate

$\frac{10,000 \times 10,004-10,002 \times 9998}{10,000 \times 10,001-10,001 \times 9999}($ Tankønyviado 1988)

\subsubsection{Experiences}

Immediate panic; discerning four sub calculations; each of these become foci in turn; commonality between left of numerator and left of denominator; catching sight of a common factor in the denominator; recognising left term of numerator as connected to difference of two squares; discerning details in the four multiplications and recognising particular relationships between them; perceiving instances of the difference of two squares as a product (first product in numerator, second in denominator); central (literally) role of 10000 then treating it as a symbol and using an $x$; simplifying the numerator as $x(x+4)-(x+2)$ $(x-2)=4(x+1)$; simplifying the denominator as; $x(x$ $+1)-(x+1)(x-1)=x+1$.

Notice that for me, replacing 10,000 with a more succinct symbol made it easier to detect, express, and exploit relationships.

Martina: I couldn't envision big groups; pictured 10 groups of 5 minus 10 groups of $3=10$ groups of 2 to recapture a sense of how the distributive property was working here... briefly wondered why I was drawn to actual numbers rather than, say, with a generalized relationship stated algebraically...even though I had full confidence that my chosen numbers were generalizable).

\subsubsection{Accounting-for responses to the Hungarian exercise}

Each time I have tackled the Hungarian exercise, I have found myself actually carrying out the difference of two squares expansions mentally. The results came into my presence unbidden, and in the case of the denominator, unhelpfully. My propensity to replace a complicated expression or large number $(10,000)$ with something more manageable (Martina used 10 instead of 10,000) was enacted as soon as paper and pen were to hand.

\subsubsection{Using the discourse of structure of attention I} started by gazing at the whole, aware of numbers, but mostly aware of resistance to calculate. I was holding the whole. Later I discerned various details such as the preponderance of 10,000 's and nearby numbers. I found myself treating the numerator as a whole, briefly holding that, then each of the products as wholes, with a brief moment of holding them, gazing at them, before discerning details. My attention went back and forth between discerning details and recognising relationships between those discerned details. At some point I perceived a property that in the two products in the numerator, the numbers differ by 4 , whereas in the denominator, they differ by 1 . I had an action become available (the phrase "come to mind" seems to me to be wholly inappropriate, as it comes to body first as an action), associated with the difference of two squares, twice in the numerator. Factoring the denominator seemed better than using the difference of two squares because of differing by only 1 . I felt vindicated that the answer was simple (4).

Martina: I couldn't quite hold this whole due to less fluency with the relationships (this is a familiar "sensation"; I know when I'm at the limit of what I'm able to mentally "lift" and my "muscles" are about to buckle and lose the entire load); I thus chose to work on numerator and denominator separately ... I had a partial urge not to calculate, but the relationships weren't quite as available in abstract form for me to immediately see the entire question as the whole. I needed to move from numbers to general in numerator and denominator separately in order to see the broader whole.

Given that the answer is 4, and more importantly that the numerator and denominator have a common factor, I have a sense of an overall property, and the desire, however weak, 
to construct other examples. What can be varied while preserving the same structure? These might involve varying the 10,000 and the other numbers appropriately, or engaging a different fine structure that will nevertheless end up with an integer answer. It even occurred to me to tinker with the relationships between the numbers so as to get $n$ as an answer.

2.3.2.2 Standing back (reflecting upon recent actions) The actions of standing back, of withdrawing from specific action and moving into a different dimension, as it were, and using this to construct a personal narrative, an own-explanation, is a vital component of meaning-making, of appreciating and comprehending. Anne Watson (private communication) pointed out that mathematically, reflection can only be manifested within a space by going up a dimension (to perform a reflection in a line in the plane physically, it is necessary to rotate about that line in 3-space). Psychological reflection has a similar quality of standing back and looking down upon the space of recent experiences.

Thinking back over what happened involves accessing and re-entering brief moments, fragments of the entire experience. Writing down accounts-of those fragments records only some of what was experienced. Indeed, writing an account-of actually changes the lived experience, which is less definite, less bound by the implied temporal structure of English, pre-articulate if not inchoate. Aspects that might have been fleeting become reified and thus experienced differently, while others that felt to be somewhere in the background may be downgraded or even eliminated.

The different forms of attention referred to in my reflections, namely.

Holding wholes (gazing)

Discerning Details

Recognising Relationships (in the particular situation)

Perceiving Properties (as being instantiated)

Reasoning on the basis of agreed properties

form a framework for discerning different ways to attend to something (including some part of something larger) (Mason 2003), but are not intended to be exclusive. They happen at different levels of detail, so one particular detail can itself become a whole, within which there are further details, and so on. These different ways of attending are, in my experience, different psychological states. Each is likely to trigger characteristic specific mathematical actions, specific mathematical actions and lines of thinking, and may require different pedagogic actions in order to bring those mathematical actions to the surface in the classroom. The same applies to analysing data, of which more in a moment.

There are close alignments between these five states and the van Hiele levels (1986) with the major difference that they are far from being 'levels', but rather states which may be present briefly or for short periods, with movement back and forth between them.

One possible consequence of this exercise is that, as you read the rest of what follows, you may perhaps choose to pay attention to (look out for, notice) what I appear to be attending to from the words that I use, and to make some conjectures about how I may be attending to it.

The fact that the Hungarian exercise was included here may have invoked a bit of trust in readers that there was some worthwhile potential, in which case that may have sustained some people to resist giving up. Evidence for this includes the expectation Martina and I both had, that there would be a simple answer. One aspect of the contract didactique Brousseau (1984, 1997) is that the learner undertakes tasks they are given, trusting that the teacher has chosen them carefully, and so that completion of the tasks (by whatever means) means that the intended learning is taking place. The tendency to 'dumb down' tasks (Stein, Grover \& Henningsen 1996), to simplify them so that learners can 'do them', is ever present, but mistakes task completion for productive experiences. More is required of the learner, and hence of the teacher. Some sense-making, some initiative to think for oneself is also required, so as to learn from the experience. This involves a combination of disposition and will, in order to overcome obstacles.

\section{Remarks about accounts-of and accounting-for}

One aspect arising from the discipline of noticing that seems to be overlooked is the precision principle. It makes a strong recommendation in the reporting of data and how it is analysed.

\subsection{The precision principle for mathematics education research}

In Mason (2002) I suggested an analogue to the Heisenberg uncertainty principle in physics, in which there is inherent and necessary uncertainty about the precision of physical measurements. For example, the product of the precision of measurement of momentum and of position is constant, so the greater the precision of one measurement, the less the precision possible for the other.

In the case of mathematics education, or indeed any social-scientific research in which data consists of observers making records in natural language of observations of people's behaviour 'extra-spectively' (observing what they can of the behaviour of others), it is not the product but the ratio of the precision of an observation of someone else's behaviour to the precision of what is revealed about the observer that is (roughly) constant. In other words, the more 
precisely someone's behaviour is described, the more that is revealed about the sensitivity of the observer to observe what is described.

In this case, the reader learns about my propensity to seek generality, and my sensitisation to the role and nature of attention (to see what and how learners are seeing). These being foregrounded, there must be many other aspects overlooked that others may find foregrounded.

One consequence of the precision principle is that it behoves the researcher to recognise and even account-for their particular propensities and sensitivities to observe certain aspects of human behaviour. A concomitant to this principle is the slogan "to express is to over-stress" (Mason $1994 \mathrm{p} \mathrm{176)}$. This is based on the observation that when I find myself expressing something to others, whether in mathematics, in mathematics education, or in mathematics education research, what I am actually experiencing as I express myself has much greater complexity that what actually gets said. What I find really hard is to remember this when listening to others: that what gets expressed is a tiny fragment of what they are experiencing. Expressing takes time and attention,. It therefore both affords access to fragments of experience, and blocks out other fragments which pass by un-noticed.

It seems to me to be important, both because of the precision principle, and because what is expressed is only a small part of what is experienced, that it behoves researchers to be upfront about the background to their particular proclivities, propensities, dispositions and sensitivities to notice what they notice, so that the reader can take this into account when considering the general validity of the observations and their relevance to future action.

\subsubsection{Accounting-for my noticing}

I can account-for what I noticed happening to me by acknowledging the urge to generalise as a feature of my mathematical thinking, an impulse developed a long time ago while I was at school. One of my pedagogic concerns has been how to encourage and foster this same impulse in learners and teachers.

I can account-for my desire to 'see what the learner was seeing' because of my ongoing interest in what people are attending to when they act. What might they be experiencing which leads them to speak or act in a particular way? I happen to know the origins of my interest in attention, because despite having lived in the UK for 50 years, people still ask me, at the end of a workshop or seminar, where my accent is from. I began to wonder what they were attending to during the session, and it gradually dawned on me that different people attend to different things at the same time, and to differing things in rapid succession, over time. Personal investigation into my own attention led me to make distinctions between ways of attending, or to different states of mind that I experienced while attending to the same 'thing'. It later transpired that there are close alignments between these states, van Hiele levels (van Hiele 1986), and the SOLO taxonomy (Biggs \& Collis 1982).

\section{Probing the data}

\section{As Italo Calvino (1983 p 55) remarked,}

It is only after you come to know the surface of things that you venture to see what is underneath. But the surface of things is inexhaustible.

It seems to me that this phenomenon bedevils mathematics education. It is so very difficult to get teachers and researchers to probe beneath the surface of their practices and of the discourse which they choose for articulating justifications for their actions. In what follows I attempt to probe beneath the surface somewhat.

This section begins by probing beneath the surface of listening (referred to by Zaslavsky in the original article from which exercise 1.1 is drawn), as an example of probing beneath the surface of an established discourse, making personal use of the Discipline of Noticing in order to sensitise oneself more fully to a typical situation and associated actions that could then be initiated.

\subsection{Probing beneath the surface of listening}

In the original article, Zaslavsky (2010) uses the reported incident to point to the need to listen carefully to what learners say. This is a sentiment with which I whole heartedly agree, though it is often easier to observe its absence in others than it is to manifest it in my own practice. Listening-to what a learner is saying, or perhaps trying-to express, is quite different from listening-for what is already in the teachers' head (Davis 1996). The discipline aspect of the Discipline of Noticing is about how to sensitise oneself to situations so as to enable an action that might otherwise be overlooked. For example, noticing a situation in which it would be preferable to listen-to what is being expressed rather than listening-for what is expected could trigger an action of suppressing what is in the teachers' head, and focussing on what the learner is expressing, or trying to express.

It is not sufficient merely to 'notice' some aspect of a situation. My personal observations have led me to see the importance of having an action become available as a result of noticing. It is not possible in the space available to introduce further exercises for readers through which they might phenomenologically come to similar conclusions for themselves. I have to depend on resonance with the accounts-of. 
Because of my focus on lived experience, for me the important question to consider is what action results from careful listening. For example, currently it seems to be popular, even expected, that the teacher, who is the 'significant other' (Stack 1953 p 6) in the classroom, overtly values what learners say and do. This is supposed then to contribute to a caring and nurturing atmosphere and a feeling of selfefficacy for the learner.

However, 'valuing' the learners' contribution is in danger of becoming a universal which overlays and blocks out critical consideration. I see mathematics education as a caring profession, as do many others (Trigwell and Prosser 1996; Goldstein 2002; Mason 2002; DeVito 2006; Noddings 2012; Watson 2019). The issue of 'over-valuing' is an instance of an underlying endemic and structural tension between 'caring for the learner' and 'caring for mathematics' (Skilling and Mason 2015). Inappropriate valuing is likely to lead to mass confusion, even cynicism, when the learner knows that what is being praised is superficial or simply 'lucky'. Furthermore, it is the actions that need to be valued, not the person, just as it is actions (e.g. 'bad behaviour') that may need to be criticised, not the person. What is most appropriate is to value the fact of a learners' contribution, while questioning what is actually said or done, and probing what is being experienced but not (yet) expressed. Distinguishing these can be vital, because the person can be valued, while their contribution can be questioned.

My preferred language for this is based around conjecturing (Pólya 1962); Mason, Burton and Stacey 1982/2010). In a conjecturing atmosphere, what is said is usually said so that it can be challenged, and where necessary, modified. Simply hearing myself say something can bring it into question as I realise that what has been expressed is not accurately reflecting what is being experienced. This is how expressing can be a learning experience for the speaker, as well as any audience. In a conjecturing atmosphere, statements are expected, even intended to be modified on the basis of personal critique, and on the basis of the responses of others, whether questioning details or suggesting possible counter examples. In a conjecturing atmosphere it is possible to praise the fact of a conjecture without praising or even judging the quality or correctness. However more is required than simply the making of a conjecture ... it must be refined and justified!

Listening is much harder than it first seems, but it can through perseverance, eventually lead to 'teaching by listening' (Davis 1996). It is very tempting to reject what is said by someone else when it does not conform to what I am expecting or looking for. As Love and Mason (1992) observe, very often when a question is asked by a teacher it is only when the teacher hears the response from the learner that they realise that they actually had an expectation, an answer they were 'looking-for'. The question arose inside them as a teacherly reaction to something they noticed which came to the surface inside them. This observation arose over time when working with learners, based on noticing in ourselves the impulse to ask a question, and very often finding a potential answer already present. This offers one reason why questioning by a teacher can so easily turn into "guess what is in my mind": our teacherly selves convert momentary noticing into questions, based around "can you see/hear what I can see/hear?".

Teaching by listening is, for me, one of six modes of interaction between teacher, learner and mathematics. (Mason 1979). In the case of the Sara-David ages incident (exercise 1.1), the learner may have experienced a desire to express what they had realised. When the mathematics (or mathematical thinking) actually initiates the action of expressing, with the teacher acting as mediator, the very presence of the teacher can help maintain the learner and the mathematics in contact. The teacher can create an environment in which the arising of a 'desire to express' is more rather than less likely, by developing a conjecturing atmosphere, and by recognising that expounding is not the only effective mode of interaction.

It may however be the case that the learner felt pressured to say something, and so an action on the numbers which became available was enacted automatically, without further consideration, possibly without anything to do with what they experienced. Or perhaps the teacher/ researcher's question prompted re-entering the action undertaken, whether thoughtfully or automatically.

Listening carefully to learners can take time and may call upon mathematical experience and sophistication on the part of the teacher beyond what appears to be the mathematical sophistication of the topic. In the present case, algebraic manipulation of the arithmetic shows that the learner is quite correct. Since we have no access to the learners' actual thought processes, attempts to 'see what the learner is seeing', to attend to the things that the learner is attending to and in the way they are attending, proves quite difficult. The only possibility is to look out for incidents in my own experience which in some way mirror or resonate with this situation.

Thus what the Discipline of Noticing offers teachers is support and methods for continuing to sensitise themselves to signs and signals from learners indicating what the learner may be attending to, and how that may be attending to it. Only then is it really possible for the teacher to choose and action that might re-direct attention appropriately for the topic of the lesson.

One good strategy for testing whether you fully appreciate and comprehend something is to attempt to generalise. In the case of the ages task: 
Denote the gap between ages by $g$, the multiplier by $m$, and the delay (the number of years previously that the multiplier was correct) by $d$. Then the ages of Sara and David turn out to be $\frac{g}{m-1}+g+d$ and $\frac{g}{m-1}+d$ respectively.

The reported action happens to work when $m=2$, but otherwise does not give the correct answer. This leads me to wonder whether what the learner was attending to was actually mathematically appropriate.

On reflection, Martina recognised that

I had multiplied 5 by 2 , then added 3. But when I first read the given learner's response, I didn't immediately see why that would give the correct answer.

I had had a nagging doubt that structurally, there was something amiss, even though the answer turned out to be correct. My intuition was validated by my generalisation.

\subsection{Probing Beneath the surface of acting out of habit}

This section uses an augmented version of Dual Systems Theory to link the effects of noticing, and use of the Discipline of Noticing, to a popular but limited view of the human psyche.

The first interpretation of the students' explanation of her method in the word problem, associates the learner's action with automaticities or habits. In order to experience this, here is a task that has been used many times but which comes from a long line of American arithmetic books:

A baseball bat and ball cost together one dollar and 10 cents. The bat costs one dollar more than the ball. How much does the ball cost? (Kahnemann and Frederick 2005 p 273)

A book and a pen cost $\$ 1.20$; the book cost $\$ 1$ more than the pen. What was the cost of each? (Jones 1930 problem $96 \mathrm{p} \mathrm{10)}$

Martina, using her slider approach immediately, suddenly realised that it is structurally the same as the Sara and David situation! On encountering this sort of task unexpectedly, most people's first thought is to 'blurt out' or at least have come to action "one dollar, and ten (in the second, twenty) cents". This can be seen as an example of System 1 in what Stanovich and West (2000) called dual systems theory, which was exploited and developed by Kahneman and Frederick (2005) and extensively by Kahneman (2012). System 1 (S1) refers to actions enacted by the body without recourse to consideration by the intellect (cognition). It could be that an identification of the difference with part of the overall cost invites a subtraction, and that the 'more than' phrase is simply overlooked (my accounting-for). System 2 (S2) refers to consideration by intellect-cognition: the frontal part of the brain. If an action can be delayed or parked, S2 may come into play, in which the action is considered (cognition) and evaluated before being enacted. Momentary consideration of my own experience (a use of S2) reveals that this is too simplistic. Some people are able to stop themselves and consider (or simply find themselves stopping and considering), while others enact the action without further consideration.

Over many years I have noticed that when an action becomes available it tends to get enacted. It is really difficult to hold back, to park an idea or a possibility. This aligns with the computer-based metaphor of the psyche as an engine with many default parameters already evaluated, and in which actions are initiated as soon as the parameters have values (Minsky 1986). That 'noticing' has alerted me to the possibility that learners' actions may be reactions, rather than considered responses, which in turn opens up questions about the reliability of many research instruments which depend on self-report responses to questions.

The idea of automaticities, actions enacted before they are considered by the forebrain, aligns with the notion of Systems 1 and 2 exploited by Kahneman (2012), but recognised in the ancient psychology of Sankhya and the Upanishads. Many teachers have also experienced one or both of the following:

You offer a mathematical task to some learners and some or all immediately say, "I can't do this" or something similar. Pens are put down and action stops.

You are offered a mathematical task and immediately emotions well up inside you and you experience a state of, "I can't do this".

I refer to incidences like these as the portcullis phenomenon, because it is as if a portcullis is dropped in front of me, blocking me from useful action (access to the fortification). One of the contributions of a conjecturing atmosphere is that instead of stopping, it is (almost always) possible to try some examples, make some conjectures, and then record these so as to be able to return later when a further idea may have occurred, and be able to pick up where I left off.

It has long been recognised that the body reacts first, usually with an action; that emotions kick in somewhat later, (Mandler 1989; Mcleod and Adams 1989; McGilchrist 2009; Kahneman 2012), and that cognition arrives on the scene considerably later still (Norretranders 1998; Illeris 2003). In order to acknowledge the role of emotions (affect) it seems important to insert a System 1.5 between S1 and S2 (Mason and Metz 2017). This acknowledges that the impetus to act may come initially from the arising of a strong emotion, possibly through metonymic associations triggering a change of state, or through metaphoric resonance with previous experiences (including childhood or other traumas). Access to an action may then sometimes follow, before S2 gets to consider it. Indeed, one of the sociological roles that 
mathematics can play is to alert learners to the fact that the first action that becomes available may not be the most sensible, and this awareness could be of assistance outside of the classroom.

The purpose and intention of the Discipline of Noticing is to increase the range of actions that become available to be enacted. Some of these may in time become habits, but this is presumably an improvement on the previous more limited range of available actions. Furthermore, the Discipline of Noticing can be used to work on developing the propensity (even habit) of parking the first action that becomes available, so shifting from S1 into S2.

Another possibility is to become stuck in a state of indecision, where S1.5 floods the channels and stymies action, when it might be sensible to enact something and then see where it leads. It seems to me that emotions are the source of actual energy (as the etymology suggests) which is channelled into some long and well established coordination or adherence (Varela 1999) of actions, emotions and cognition. Because they may persist and repeat, coordinations can also be referred to as adherences between actions, feelings and thoughts, and states of attention and willpower.

Traditionally, sets of coordinations or adherences have been called selves (Bennett 1964; Roberts and Donahue 1994) with associated frames of mind that are disposed to 'fire' (Minsky 1975, 1986) or come to the fore (Hudson 1968). However some people reject the notion of multiple selves as they see themselves (sic) as engaged in a search for their 'true self'. Varela (1999) referred to coordinations as micro-identities, because for a moment they 'become us': we are, momentarily at least, the 'person' driven by coordinations of actions, feelings, cognition, attention, and will. At any moment, some coherence or coordination dominates, generating our behaviour and our experience. This corresponds to the ubiquitous metaphor of the human psyche as the ship of state (Plato see Hamilton \& Cairns 1961), or the collection of servants running a large mansion (Jung: see Olney 1972 p 110) or a horse-drawn carriage (Gurdjieff 1950 pp 1193-1119). Houston (1997 p 30) used the term polyphrenia for "the orchestration of our many selves-our extended health. We have a vast crew within."

There is a fourth 'system' or state which seems not to find a comfortable home in dual systems theory, and which deserves to be labelled as S3. It is a centred state in which $\mathrm{S} 1, \mathrm{~S} 1.5$, and $\mathrm{S} 2$ have quietened down, permitting access to something 'deeper' or 'beyond'. This is the gateway to insight and creativity, allowing a refined energy to enter the situation (Bennett 1964). T. S. Eliot called it "the still point of the turning world" and developed the idea in the Four Quartets, particularly East Coker and Burnt Norton. Various authors (Synectics: Gordon 1961; U Theory: Scharmer 2007) have indicated ways to prepare for it, which is what one interpretation of the parable of the wise and foolish virgins recommends. However S3 cannot be forced or mechanically reproduced. It can sometimes be experienced as l'esprit d'escalier (the thought on the staircase afterwards) when a more appropriate action becomes available too late to be enacted.

Dual systems theory, with the addition of two further systems, provides one discourse through which to report, record and reflect upon aspects of one's own functioning. By reflecting-on-action (Schön 1983, 1987, 1991) and then pro-flecting, that is, imagining oneself acting freshly in the future in some characteristic setting, it is possible to become aware of the automatic habitual functioning of S1, and the characteristic spurts of energy from S1.5 which activate particular coordinations (selves), but which could also be used to inform consideration by $\mathrm{S} 2$. The important point of such work at sparking and sensitising oneself to notice more finely and more broadly, lies in distinguishing between accounts-of, and accounting-for what is noticed in some chosen discourse.

For teachers this means re-flecting in detail (analysing accounts-of, selecting situations and associated actions to use in the future), so as to pro-flect usefully (imagining those actions becoming available in predictable situations) so as to open up access to possible actions in the moment (flection) in future.

\section{Beyond the tripartite psyche}

My time with J. G. Bennett in the 1970s acquainted me with aspects of ancient psychology. I got the impression that Sankhya philosophy could be an origin for the now common tripartite structure of the psyche, namely enaction, affect and cognition. Through self-observation, as in the discipline of noticing, I have become aware of the additional importance of attention, will, and witness, which often seem to be overlooked yet significant aspects of human psyche (Mason and Metz 2017). What follows are brief notes on each of these further aspects of the psyche. Identified and elaborated through the use of the Discipline of Noticing, they augment available discourse to enable probing beneath the surface of human psyche involved in learning and teaching.

\subsection{Attention}

Clearly not only what people are attending to, but in what way, influences which ways of thinking, feeling, and acting are likely to be activated, and so what actions are likely to be enacted and consequently observed by others. It is helpful to think in terms of coordinations between the way energy is released by the emotions, colours thought, and influences actions, because these typicalities are often quite stable over 
time. For example, once the portcullis has dropped several times, it becomes a habit. As the Zen saying has it,

\section{Habit forming can be habit forming! (Shigematsu} 1981)

This captures the experience of finding it difficult to take up a new idea or to take on a different perspective, to see things in a different way, or to think of an alternative action. One of the marks of an expert is the way in which an action, unexpected by the novice, is enacted. One way to become more expert is by developing a plethora of available actions (and hence coordinations), which is what the Discipline of Noticing is designed to achieve.

Attention is worthy of focus because of the different ways or the different states one can be in when attending to the same thing (Mason 2003), and because of the well-known phenomenon that a teacher notices things happening in classrooms that non-teachers do not, which is itself a special case of the widely recognised phenomenon that professionals notice details to which the novice is oblivious.

For example, initiating the pedagogic action of inviting, even prompting, the construction of personal narratives or own-explanations (Chi and Bassok 1989; Chi, Bassok, Lewis, Reiman and Glasser 1989) amongst learners who are otherwise content merely to assent to what they are told, is unlikely to produce productive narratives that might be recalled and used to inform future action, whereas learners who are accustomed to taking an assertive stance are more likely to have recourse to informative 'stories' (Mason 2009).

Becoming aware of the shifts of their own attention can alert teachers to worthwhile shifts in learner attention, opening up possibilities for pedagogical actions to bring these about.

\subsection{Will}

Although many philosophers identify will and attention, it seems to me that they can be distinguished. There is some aspect of the psyche which enfolds, envelopes, and influences what coordination-adherences become available and how much investment there is in them, how much energy is allocated to them. Inspired by my school motto (Velle est Posse: where there's a will there's a way), I associate this with will. For example, I can attend to the value/need to act, but not have sufficient will-power. I can even have an action become available (to complete an exposition of a mathematical result by inserting all the details, or to undertake some maintenance task around the house) and yet not muster enough energy to enact it. Thus a learner who enters the classroom predisposed (affect) not to engage or to find it 'all too difficult' has already leaked away necessary will power to sustain them through a period of not comprehending temporarily in the hope and expectation of comprehending later. Developing resilience is clearly an important part of learning mathematics, as it is in learning or doing anything (Claxton 1984, 1997), in order to set aside past anxieties, experience the dopamine rush of insight, and proceed to the next task just a little more willing to try harder.

Will is essential in any discussion concerning mathematics education in particular, but any research programme in social sciences in general, because the degree and form of initiative being taken matters enormously when trying to make sense of and interpret someone else's behaviour. Learners who are content to assent-to what they are being told, or asked to do, or who don't trust themselves, are likely to invest the minimum amount of energy in completing the tasks they have been set. They easily fall prey to the didactic tension in which the more clearly the teacher articulates the behaviour being sought, the easier it is for the learners to display that behaviour, without generating it from themselves, and hence being less likely to generate it again in the future (Mason \& Davis 1989). By contrast, learners who adopt an assertive stance take initiative, challenge, and think things through for themselves.

\subsection{Witness}

Being in flow That which observes without commenting or judgment I refer to as the witness, as indicated in a stanza from the Rg Veda:

Two birds, close yoked companions,

Bothe clasp the self-same tree.

One east of the sweet fruit,

The other looks on without eating (Bennett 1943).

Bennett saw the eating bird as the 'doing' part of the psyche, which is usually taken to be comprised of enaction, affect and cognition, or in less formal terms, as behaviour, emotion and thought. The technical vocabulary can be useful because thinking often subsumes all three aspects in common parlance. The second bird is the witness, the executive monitor (Schoenfeld 1985, 1992). It is the source of inner questioning such as "why am I doing this?", "is this the best choice to make?", and the like.

The witness, the second bird, which watches and comments, is really helpful in mathematics, because it can alert me to question why I am carrying out some action that is looking increasingly complicated. It is helpful in teaching, as the inner voice that says things like "participants are struggling" or "we need a change of energy now". It is helpful in research by asking things like "am I collecting data because I need it, or as displacement activity?" and "what will I actually do with responses to these probes?" or "do I really believe what subjects say in response to this question?". Here I have been using the verb saying in a metaphorical 
sense because it is not for me a voice as such, only a sensitivity linked, usually, to a possible action.

Developing an inner witness, monitor or executive is what the Discipline of Noticing is designed to support (Mason 2002).

\subsection{The integrated psyche}

The upshot of these considerations arising from my own noticing is that the human psyche has a complex structure. We each have multiple coordinations (adherences, microselves, selves). Different qualities of energy arising in or associated with affect, flow through prepared channels of action and cognition, giving rise to characteristic actions and thoughts. These influence both what is attended to, and how, providing blinkered sensitivities and trammelled patterns of wilfulness. An independent witness affords access, to a lesser or greater extent depending on its development and activation by current coordinations, to reminders to withdraw from action and consider (move from S1 and S1.5 to $\mathrm{S} 2$ or even $\mathrm{S} 3$ ).

Not only is the six-fold structure of the psyche help teachers distinguish possible origins of behaviour, thoughts and emotions in themselves, but it can assist teachers in coping with the complex psyche of their learners. Increased sensitivity is likely to enable a broader range of actions, and so provide teachers with greater choice of pedagogical actions which in turn, may assist learners to shift their attention appropriately and increase their sensitivity to notice mathematical situations, and so in turn, to act freshly and perhaps more appropriately.

\section{Validating noticing}

I begin with a review of the epistemological conundrum facing social-sciences concerning validation. Whereas scientific experiments and physical measurements can be repeated, observations about human behaviour are notoriously difficult to replicate, due, in part, to the imprecision of natural and even technical language as to what actions were actually enacted, and in what specific context. I proceed therefore with a series of quotations before showing that the Discipline of Noticing includes a systematic validation process which formalises what human beings actually do informally, if usually unsystematically.

It is well known that it is very easy to be deceived by what one thinks one has noticed.

Facts are theory laden (Hanson 1958)

We want our theories to be as fact-based as our facts are theory-based. (Goodman 1978)
The Universe is a mirror in which we can contemplate only what we have learned to know in ourselves. (Italo Calvino 1983 p 107)

Observation, and even forming a collection of observations is not in itself sufficient:

A succession of experiences does not add up to an experience of that succession. (various)

As T. S. Eliot (1941) observed that, in a moment of happiness:

We had the experience but missed the meaning, And approach to the meaning restores the experience In a different form.

The search for objectivity so that research arrives at 'truth' has seen social sciences attempting to mimic physical sciences through reliance on measurement. The Discipline of Noticing provides an alternative way to seek validation. To notice is to make a distinction: this not that. That distinction is then expressed in words, with attendant unexpressed aspects in the background.

The important question is whether discerning that distinction enables an appropriate action to be initiated. Bateson (1973) reminds us that it is the "difference that makes a difference that matters", or put another way, some differences are worth attending to while others are not. The coupling of a distinction and an action is what Gattegno refers to as an awareness, which includes both conscious and unconscious 'awareness' in the ordinary sense. Humberto Maturana observed this close coupling in his much quoted assertion that.

Language is the consensual coordination of the consensual coordination of action (Maturana 1988).

Here consensual means 'jointly-sensed', not negotiated or otherwise. To work on this and other quotations I am using really requires the accumulation of task-exercises through which others can approach a 'consensual' coordination of action, and then use the quotation for the consensual coordination of those consensual coordinations. That is what a phenomenological approach to enquiry-research involves.

The adjective appropriate is itself open to scrutiny, through further observation and noticing. What constitutes an 'appropriate action' in any given situation? For groups committed to some ideological stance or collection of acceptable actions, an appropriate action would have to conform to the norm. But perhaps there could be a growing realisation that there is no 'best' action in any situation, only possibilities from amongst which to choose; that what matters is being able to justify one's choice of action in some acknowledged discourse, coupled with appreciation of that momentary freedom to choose. 
The question then arises as to whether the distinction and any associated action is part of a self-delusion, part of an ideological commitment or underpinning assumption. The only way to test this is to engage other people in making that distinction and testing that action in their own experience. So the disciplined noticing-researcher is constantly (well, frequently) engaging people from outside the group of already-committed folk, in order to maintain a freshness and not permit distinction and action to become so automated that they block out any alternative insights.

Validation of distinctions (and relationships, and properties) through the Discipline of Noticing requires ongoing checking against the experience of others, who themselves engage in this ongoing process with yet others. Francis Bacon put it this way:

So knowledge, while it is in aphorisms and observations, it is in growth; but once it is comprehended in exact methods, it may perchance be further polished and illustrated, and accommodated for use and practice; but it increaseth no more in bulk and substance. (Francis Bacon 1609)

\section{As Paul Feyerabend put it:}

All you can do, if you really want to be truthful, is to tell a story (Feyerabend 1991, p 141)

All research 'findings' are at best 'stories' that are told. Validity has to be personal, through metaphoric resonance with personal experience, and metonymic recognition, leading to informed action in the future.

"[T]he real trick [I hope] is what happens when the stories are set side by side" (Bateson 1973, p. 35).

It is in discerning sameness and difference within multiplicity that it is possible to become aware of dimensions of possible variation and permissible change (Watson and Mason 2002) making it possible to learn (Marton and Booth 1997, Marton 2015).

For example, the Zaslavsky incident could act as a trigger in the future, to try to put observed actions into a more general context in order to test their overall validity, and to try to enter the world of the speaker, to see things as they see them, to attend to what they are attending to, and in a similar manner.

From the Upanishads.

It is not speech that one should seek to understand; one should know the speaker. [Kena Upanishad II.13]

Every observation made speaks as much about the observer as it does about what is observed.
Reality is not an experience, it is an argument in an explanation. (Maturana 1988 p 39).

Ginsburg (1987) rehearses the evolution of clinical interviews with individuals or pairs of learners. They arose from Piaget's observation that standardised tests only enable comparisons of performance between large populations. They do not provide insight into what learners are experiencing, nor do they provide access to unusual or unexpected behaviour (Ginsburg 1987 p 5). Clinical interview offers that insight. Phenomenographic studies (Marton 1981) develop this further to consider the behaviour of a small group of subjects with the aim of charting the scope and range of descriptions of different interpretations, different meanings experienced by subjects. This could perhaps be used to prepare the ground for more detailed large-scale standardised testing, again with the usual caveats, but it is more useful in alerting teachers (and researchers) to the complexity of the human psyche and implications for practice, whether in teaching or in researching.

\section{Final reflections}

Bearing in mind the etymology of theory as 'a way of seeing', it seems to me that 'theories' in mathematics education are ways of seeing. They are sets of distinctions which can be made, as part of a stylised discourse. Whether they inform practice is another matter, because being wedded to a particular theory, a particular way of seeing, a particular set of distinctions both encourages everything to be shoe-horned into that discourse, and discourages seeing differently. These in turn form coordinations (selves) through the linking of actions, emotions and energy, considerations (cognition), particular things to attend to, and ways of attending to them, and the availability and exercise of will.

The discipline of noticing as a set of practices are specific actions that can be enacted while trying to probe beneath the surface of observations and experiences. These can be used within any research paradigm or other theory. Indeed I often encourage researchers, before they impose their theories on whatever they have collected as data, to consider first not only what they would be likely to be attending to, and in what way, in order to behave as their subjects have done, but also to consider and articulate their own sensitivities which lead them to notice (and or probe for) particular behaviours enacted by their subjects.

The Discipline of Noticing as a research paradigm itself, as a way of researching your own practices, provides a philosophically well-founded method of enquiry. Insights achieved using it can be validated as described earlier, through seeking resonance with ever-expanding groups of people. 
The Discipline of Noticing as a way of being provides a basis for working on oneself, for coming to know oneself, or even, one's selves or coordination-adherences. That does not mean that change is easy, nor even, in many situations, possible. But awakening and feeding the second bird, nurturing and strengthening the inner witness, is a significant step on the path from birth to death.

Acknowledgements I am deeply grateful to Martina Metz who added observations and insights to an early draft, and to Gabriele Kaiser for her thoughtful suggestions.

Funding The author is grateful to the University of Oxford as Senior Research Fellow, and to the Open University as Prof Emeritus for enabling access to libraries.

Open Access This article is licensed under a Creative Commons Attribution 4.0 International License, which permits use, sharing, adaptation, distribution and reproduction in any medium or format, as long as you give appropriate credit to the original author(s) and the source, provide a link to the Creative Commons licence, and indicate if changes were made. The images or other third party material in this article are included in the article's Creative Commons licence, unless indicated otherwise in a credit line to the material. If material is not included in the article's Creative Commons licence and your intended use is not permitted by statutory regulation or exceeds the permitted use, you will need to obtain permission directly from the copyright holder. To view a copy of this licence, visit http://creativecommons.org/licenses/by/4.0/.

\section{References}

Bateson, G. (1973). Steps to an ecology of mind. London: Granada. Bennett, J. (1943). Values. Kingston-Upon-Thames: Coombe Springs Press.

Bennett, J. (1964). Energies: material, vital, cosmic. London: Coombe Springs Press.

Bennett, J. (1976). Noticing. The sherborne theme talks series 2. Sherborne: Coombe Springs Press.

Biggs, J., \& Collis, K. (1982). Evaluating the quality of learning: The SOLO taxonomy. New York: Academic Press.

Brousseau, G. (1984). The crucial role of the didactical contract in the analysis and construction of situations in teaching and learning mathematics. In H. Steiner (Ed.), Theory of mathematics education, paper 54 (pp. 110-119). Bielefeld: Institut fur Didaktik der Mathematik der Universitat.

Brousseau, G. (1997). Theory of didactical situations in mathematics: Didactiques des mathématiques, 1970-1990. N. Balacheff, M. Cooper, R. Sutherland, \& V. Warfield (Trans.). Dordrecht: Kluwer.

Calvino, I. (1983). Mr Palomar. London, UK: Harcourt, Brace \& Jovanovitch

Chi, M., \& Bassok, M. (1989). Learning from examples via self-explanation. In L. Resnick (Ed.), Knowing, learning and instruction: Essays in honour of Robert Glaser. Hillsdale: Erlbaum.

Chi, M., Bassok, M., Lewis, P., Reiman, P., \& Glasser, R. (1989). Selfexplanations: How students study and use examples in learning to solve problems. Cognitive Science, 13, 145-182.

Claxton, G. (1984). Live and Learn: An introduction to the psychology of growth and change in everyday life. London: Harper and Row.

Claxton, G. (1997). Hare brain, tortoise mind: Why intelligence increases when you think less. London: Fourth Estate.
Davis, B. (1996). Teaching mathematics: Towards a sound alternative. New York: Ablex.

DeVito, J. (2006). Teaching as relational development. New Directions for Teaching and Learning, 26, 51-59.

Eliot, T. S. (1941). (Gorman, D. 2000 online text). The dry salvages; part 1 number 3 of the four quartets. London: Faber \& Faber.

Feyerabend, P. (1991). Three dialogues on knowledge. Oxford, UK: Blackwell.

Gattegno, C. (1970). What we owe children: The subordination of teaching to learning. London: Routledge \& Kegan Paul.

Gattegno C. (1975/1988). The mind Teaches the Brain. New York: Educational Solutions.

Ginsburg, H. (1987). The clinical interview in psychological research on mathematical thinking: Aims, rationales. Techniques. For the Learning of Mathematics, 1(3), 4-11.

Goldstein, L. (2002). Reclaiming caring in teaching and teacher education. New York: Peter Lang.

Goodman, N. (1978). Ways of world making. Hassocks: Harvester press.

Gordon, W. (1961). Synectics. New York: Harper Row.

Gurdjieff, G. (1950). All and everything: Beelzebub's tales to his grandson. London: Routledge \& Kegan Paul.

Hamilton, E., \& Cairns, H. (Eds.). (1961). Plato: The collected dialogues including the letters. The Republic VI (488a-489d). Bollingen Series LXXI. Princeton: Princeton University Press.

Hanson, N. (1958). Patterns of discovery: An enquiry into the conceptual foundations of science. Cambridge: Cambridge University Press.

Houston, J. (1997). A passion for the possible: A guide to realizing your true potential. San Francisco: Harper SanFrancisco.

Hudson, L. (1968). Frames of mind. London: Methuen.

Illeris, K. (2003). Three dimensions of Learning: contemporary learning theory in the tension field between the cognitive, the emotional and the social. Malabar: Krieger.

Jones, S. (1930). Mathematical wrinkles (4th ed.). Nashville: Jones.

Kahneman, D. (2012). Thinking fast, thinking slow. London: Penguin.

Kahneman, D., \& Frederick, S. (2005). A model of heuristic judgment. In K. Holyoak \& R. Morrison (Eds.), The Cambridge handbook of thinking and reasoning (pp. 267-293). Cambridge: Cambridge University Press.

Love, E., \& Mason, J. (1992). Teaching mathematics: Action and awareness. Milton Keynes: Open University.

Mandler, G. (1989). Affect and Learning: causes and consequences of emotional interactions. In D. McLeod \& V. Adams (Eds.), Affect and mathematical problem solving: New perspectives (pp. 3-19). London: Springer-Verlag.

Marton, F. (1981). Phenomenography: Describing conceptions of the world around us. Instructional Science, 10, 177-200.

Marton, F. (2015). Necessary Conditions for Learning. Abingdon, UK: Routledge.

Marton, F., \& Booth, S. (1997). Learning and awareness. Hillsdale: Lawrence Erlbaum.

Mason, J. (1979). Which medium, Which Message. Visual Education. pp. 29-33.

Mason, J. (1994). Researching From the Inside in Mathematics Education: locating an I-You relationship. In J. Ponte \& J. Matos J. (Eds.). Proceedings of PME XVIII. Lisbon, Portugal. 176-194.

Mason, J. (2002). Researching your own practice: The discipline of noticing. London: RoutledgeFalmer.

Mason, J. (2003). Structure of attention in the learning of mathematics. In J. Novotná (Ed.), Proceedings, International Symposium on elementary mathematics teaching (pp. 9-16). Prague: Charles University.

Mason, J. (2009). From assenting to asserting. In O. Skvovemose, P. Valero, \& O. Christensen (Eds.), University science and mathematics education in transition (pp. 17-40). Berlin: Springer. 
Mason, J. (2016). Rising above a cause-and-effect stance in mathematics education research. JMTE, 19(4), 297-300.

Mason, J. (2017). Rising above a cause-and-effect stance in mathematics education research. In M. Pitici (Ed.), The best writing on mathematics 2017. Cambridge: Princeton University Press.

Mason, J., Burton, L., \& Stacey, K. (1982/2010). Thinking mathematically (Second Extended Edition). Harlow: Prentice Hall (Pearson).

Mason, J., \& Davis, B. (2013). The importance of teachers' mathematical awareness for in-the-moment pedagogy. CJSMTE, 13(2), $182-197$.

Mason, J. \& Davis, J. (1989). The Inner Teacher, The Didactic Tension, and Shifts of Attention. In G. Vergnaud, J. Rogalski, \& M. Artigue, (Eds.) Proceedings of PME XIII. Paris. vol 2, 274-281.

Mason, J., \& Metz, M. (2017). Digging Beneath Dual Systems Theory and the Bicameral Brain: abductions about the human psyche from experience in mathematical problem solving. In U. Xolocotzin (Ed.), Understanding emotions in mathematical thinking and learning (pp. 379-407). Cambridge: Elsevier/Academic Press.

Maturana, H. (1988). Reality: the search for objectivity or the quest for a compelling argument. Irish Journal of Psychology., 9(1), 25-82.

McGilchrist, I. (2009). The master and his emissary: The divided brain and the making of the Western World. New Haven: Yale University Press.

Mcleod, D., \& Adams, V. (Eds.). (1989). Affect and mathematical problem solving: A new perspective. New York: Springer-Verlag.

Minsky, M. (1975). A framework for representing knowledge. In P. Winston (Ed.), The psychology of computer vision (pp. 211-280). New York: McGraw Hill.

Minsky, M. (1986). The society of mind. New York: Simon and Schuster.

Noddings, N. (2012). The caring relation in teaching. Oxford Review of Education, 38(6), 771-781.

Norretranders, T. (1998). (J. Sydenham Trans.). The user illusion: Cutting consciousness down to size. London: Allen Lane.

Olney, J. (1972). Metaphors of self: The meaning of autobiography. Cambridge: Princeton University Press.

Pólya, G. (1962). Mathematical Discovery: on understanding, learning, and teaching problem solving (combined edition). New York: Wiley.

Roberts, B., \& Donahue, E. (1994). One personality, multiple selves: Integrating personality and social roles. Journal of Personality, 62(2), 199-218.

Scharmer, O. (2007). Theory U: Leading from the future as it emerges. The social technology of presencing. Cambridge: The Society for Organizational Learning.

Schoenfeld, A. (1985). Mathematical problem solving. New York, USA: Academic Press.

Schoenfeld, A. (1992). Learning to Think Mathematically: problem solving, metacognition, and sense-making in mathematics. In D.
Grouws (Ed.), Handbook for research on mathematics teaching and learning (pp. 334-370). New York: MacMillan.

Schön, D. (1983). The reflective practitioner: How professionals think in action. London: Temple Smith.

Schön, D. (1987). Educating the reflective practitioner. London: Jossey-Bass.

Schön, D. (Ed.). (1991). The reflective turn: Case studies in and on educational practice. New York: Teachers College, Columbia University.

Shah, I. (1964). The sufis. London: Jonathon Cape.

Shah, I. (1978). Learning how to learn. London: Octagon.

Shigematsu, S. (1981). A Zen forest. New York: Weatherhill.

Skilling, K. \& Mason, J. (2015). Spaces of Values: what is available to be adopted by students. In O. Helenius (Ed.), Proceedings of MADIF 9 (pp. 137-147).

Stack, S. (1953). The interpersonal theory of psychiatry. New York: Norton.

Stanovich, K., \& West, R. (2000). Individual Differences in Reasoning: implications for the rationality debate. Behavioral and Brain Sciences., 23, 645-726.

Stein, M., Grover, B., \& Henningsen, M. (1996). Building student capacity for mathematical thinking and reasoning: An analysis of mathematical tasks used in reform classrooms. American Educational Research Journal, 33(2), 455-488.

Tankønyviado (1988). Budapest isbn 9631814408 .

Trigwell, K., \& Prosser, M. (1996). Changing approaches to teaching: A relational perspective. Studies in Higher Education., 21(3), 275-284.

van Hiele, P. (1986). Structure and insight: A theory of mathematics education. Developmental Psychology Series. London: Academic Press.

Varela, F. (1999). Ethical know-how: Action, wisdom, and cognition. Stanford: USA Stanford University Press.

Watson, A. (2019). Equality, truth and love in subject teaching: cognitive care in the case of mathematics. In D. Rowe \& A. Watson (Eds.), Faith and experience in education: Essays from quaker perspectives (pp. 63-91). London: Trentham Books.

Watson, A., \& Mason, J. (2002). Student-generated examples in the learning of mathematics. Canadian Journal of Science, Mathematics and Technology Education, 2(2), 237-249.

Zaslavsky, O. (2010). The challenge of listening. JMTE, 13(1), 3-4.

Publisher's Note Springer Nature remains neutral with regard to jurisdictional claims in published maps and institutional affiliations. 